\title{
BASE SPECIFIC CHEMICALS AND MUTATION ANALYSIS IN LYCOPERSICON
}

\author{
H. K. JAIN, R. N. RAUT and Y. G. KHAMANKAR \\ Genetics Division, Indian Agricultural Research Institute, \\ New Delhi
}

Received 12.viii.67

\section{INTRODUGTION}

Some chemicals are quite specific in reacting with particular bases of DNA molecules (see Freese, 1963). Thus, the reactivity of hydroxylamine with cytosine at a particular $p \mathrm{H}$ is 30 times greater than that with other commonly occurring DNA bases (Freese et al., 1961; Brown and Schell, 1961; Malling, 1966). Hydrazine, on the other hand, reacts specifically with thymine under particular experimental conditions (Freese et al., 196lb; Salganik, 1963). Base specific chemicals of this nature, and also base analogues, induce mutations in micro-organisms but they have rarely been tested for mutagenic action on higher organisms. Alkylating agents, like ethyl methane sulfonate (EMS), induce mutations in both micro- and higherorganisms, but their specificity does not appear to be as complete (see Krieg, 1963). Further, even in the case of EMS and other chemicals of this nature, few studies on higher organisms have been based on the specific locus method.

The chemical mutagens indicated above and ionising radiation have been tested for their effect on genes of tomato. The commonly cultivated tomato is very favourable for genetic analysis because it offers a number of mutant genes showing good expressivity and its chromosomes have been extensively mapped (Rick and Butler, 1956; Clayberg et al., 1960, 1966).

The mapped genes in tomato, whose number exceeds 150, show a highly asymmetrical distribution in that a few of the 12 chromosomes account for a disproportionately large number of them. No satisfactory explanation has been offered for this asymmetry and some of the findings from the present experiment may be of interest in relation to this observation.

\section{Materials and methods}

(i) Treatments. Seeds of Lycopersicon esculentum variety Improved Meeruti were obtained from a single bulk population. Samples of 500 or more seeds were presoaked in water for various times and treated with different concentrations (table 1 ) of hydroxylamine $\left(\mathrm{NH}_{2} \mathrm{OH} . \mathrm{HCl}\right)$, hydrazine $\left(\mathrm{NH}_{2} \cdot \mathrm{NH}_{2} \cdot 2 \mathrm{HCl}\right)$ and ethyl methane sulfonate $\left(\mathrm{C}_{2} \mathrm{H}_{5} \mathrm{OSO}_{2} \mathrm{CH}_{3}\right)$. The hydroxylamine and EMS solutions were prepared in phosphate buffer and the $p \mathrm{H}$ was adjusted to 7 with $\mathrm{NaOH}$. The hydrazine solution was parepred in borate buffer and $\mathrm{NaOH}$ was used for the final adjustment of $p \mathrm{H}$ to $8 \cdot 5$. All the treatments were given in petri-dishes at a temperature of $25^{\circ} \mathrm{C}$., using freshly prepared solutions. In the control series, seeds were kept before sowing in the corresponding buffer solution, free of mutagenic chemical (table 2). Also gamma radiation from a cobalt-60 source was 
given to dry seeds. Different treatments within a series were initiated simultaneously and seedlings from different treatments were raised under identical conditions.

TABLE 1

Types and frequency of $M_{1}$ mutant seedlings

\begin{tabular}{|c|c|c|c|c|c|}
\hline \multirow{2}{*}{\multicolumn{2}{|c|}{$\begin{array}{l}\text { Code numbers and details } \\
\text { of treatments }(500 \text { seeds } \\
\text { each treatment) }\end{array}$}} & \multicolumn{4}{|c|}{$\begin{array}{l}\text { Frequency of different mutant seedlings } \\
\text { (percentage of } M_{1} \text { plants) }\end{array}$} \\
\hline & & Dwarf & $\begin{array}{c}\text { Without } \\
\text { anthocyanin }\end{array}$ & $\begin{array}{l}\text { Dwarf and } \\
\text { without } \\
\text { anthocyanin }\end{array}$ & Woolly \\
\hline \multicolumn{6}{|c|}{ Hydrazine ( $p \mathrm{H} 8 \cdot 5)$} \\
\hline (1) & $* 0 \cdot 05,30,24$ & $1 \cdot 13$ & 1.06 & $0 \cdot 80$ & $2 \cdot 66$ \\
\hline (2) & $0 \cdot 10,0,30$ & 1.05 & $0 \cdot 69$ & $0 \cdot 36$ & $1 \cdot 39$ \\
\hline (3) & $0 \cdot 10,12,24$ & $1 \cdot 30$ & 0.86 & $0 \cdot 43$ & $1 \cdot 30$ \\
\hline (4) & $0 \cdot 10,16,20$ & 1.96 & 0.98 & $0 \cdot 19$ & $1 \cdot 30$ \\
\hline (5) & $0 \cdot 10,16,30$ & 0.44 & 一 & 1.00 & $0 \cdot 50$ \\
\hline (6) & $0 \cdot 10,16,40$ & 0.95 & 0.97 & 0.63 & 0.63 \\
\hline (7) & $0 \cdot 06,16,12$ & 0.93 & 0.95 & 0.63 & 0.93 \\
\hline (8) & $0.05,16,30$ & 0.22 & $0 \cdot 62$ & - & 0.44 \\
\hline \multicolumn{2}{|c|}{$\mathrm{MS}(p \mathrm{H} 7 \cdot 0)$} & Dwarf & \multicolumn{2}{|c|}{ Chlorophyll deficient } & Woolly \\
\hline (1) & $0 \cdot 05,30,24$ & - & \multicolumn{2}{|c|}{$2 \cdot 37$} & - \\
\hline & $0.05,0,30$ & - & \multicolumn{2}{|c|}{0.69} & - \\
\hline (3) & $0.03,12,24$ & - & \multicolumn{2}{|c|}{$1 \cdot 50$} & - \\
\hline (4) & $0.03,16,20$ & - & \multicolumn{2}{|c|}{$1 \cdot 09$} & 0.42 \\
\hline (5) & $0.03,16,30$ & 0.44 & \multicolumn{2}{|c|}{$2 \cdot 09$} & - \\
\hline (6) & $0.03,16,40$ & - & \multicolumn{2}{|c|}{$2 \cdot 47$} & - \\
\hline (7) & $0.02,20,12$ & - & \multicolumn{2}{|c|}{$0 \cdot 86$} & - \\
\hline
\end{tabular}

Hydroxylamine $(p \mathrm{H} \mathrm{7.0)}$

(1) $0 \cdot 01,30,24$. (2) $0 \cdot 02,0,30$. (3) $0 \cdot 02,12,24$. (4) $0 \cdot 05,16,20$. (5) $0 \cdot 05,16,30$. (6) $0.025,20,12$. (7) $0 \cdot 012,20,30$.

No mutants observed in any of these treatments.

Gamma rays

(1) 30 k-rads. (2) 30 k-rads. (3) 20 k-rads. (4) $30 \mathrm{k}$-rads. (5) $40 \mathrm{k}$-rads. No mutants observed in any of these treatments.

* Molar concentration, pre-soaking hours and treatment hours respectively.

(ii) Scoring. Mutations were scored in the $\mathrm{M}_{1}$ and $\mathrm{M}_{2}$ generations $\left(\mathrm{M}_{1}\right.$ : plants raised from treated seeds; $\mathrm{M}_{2}$ : plants raised from seeds of selfed $M_{1}$ plants). The scoring in the $M_{1}$ material was confined mostly to the seedling stage. The tomato plant offers an advantage in this respect, because a number of genes affecting seedling characters give such a characteristic phenotype that mutation at previously known loci can be readily scored. Further, a group of "control" mutants, obtained from Dr Butler, was available for comparison and for tests of allelism and this facilitated the scoring of mutations at specific loci. Not all the induced variation could, however, be traced to the mutation of known genes. The non-specific mutants with the exception of grossly chlorophyll deficient seedlings could not be considered. 


\section{Experimental results}

The treatment with mutagens affected seed germination so that the number of $\mathbf{M}_{\mathbf{1}}$ seedlings varied from 35.8 to 64.6 per cent. of the treated seeds in the case of the different hydrazine treatments. The corresponding values in the case of hydroxylamine, EMS and gamma radiation were $28 \cdot 2$ to $50 \cdot 2,32 \cdot 0$ to $69 \cdot 6$ and $48 \cdot 6$ to 64.8 respectively ( $c f$. Controls, table 2).

TABLE 2

Observations on the control series ( 500 seeds per treatment)

Treatment

Borate buffer ( $p \mathrm{H} 8.5$ )

$$
\text { *0, } 30
$$

16,30

28,17

26,28

25,28

Phosphate buffer ( $p \mathrm{H} \mathrm{7 \cdot 0)}$
Percentage germination
Type and frequency
of mutants
$72 \cdot 2$

$64 \cdot 8$

$71 \cdot 7$

$71 \cdot 9$

$89 \cdot 6$

$76 \cdot 6$

$61 \cdot 6$

$77 \cdot 6$

$80 \cdot 8$

$62 \cdot 2$

$78 \cdot 4$

$96 \cdot 0$

$86 \cdot 2$

$94 \cdot 0$

$88 \cdot 4$

$80 \cdot 0$
Without-anthocyanin $0 \cdot 22$ per cent.

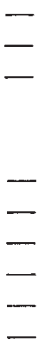

Dry seeds (different lots)

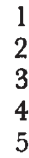

5

* Pre-soaking hours and treatment hours respectively.

(i) Induced gene mutations. The mutants were classified after Rick and collaborators (loc cit.) and included dwarfs, woolly, chlorophyll-deficient and anthocyaninless, all of which could be scored at the seedling stage. Brachytic, dilute, broad leaved, climbing and some other types of mutant were scored at the adult stage (tables 1 and 3).

Dwarf, woolly, anthocyaninless and mutants showing combined dwarf and anthocyaninless, all recovered in the $\mathbf{M}_{1}$ material, have been maintained over five generations in small progenies of 10-30 plants. They continued to breed true with the exception of woolly, which always segregated to give woolly and normal plants. Woolly is known to be dominant and lethal in the homozygous condition. The dilute and climbing mutants recovered in the $\mathbf{M}_{2}$ generation also have been maintained over several generations and continue to breed true. The brachytic and some other mutants were lost in the earlier generations. Two series of crosses were made to determine the nature of the induced mutations and to identify some of the loci involved. In the first series, a number of randomly selected mutant plants of the dwarf and woolly types observed in the $\mathbf{M}_{1}$ material, and some other mutants obtained in the $\mathbf{M}_{2}$ cultures, were crossed with normal plants from 
H. K. JAIN, R. N. RAUT AND Y. G. KHAMANKAR

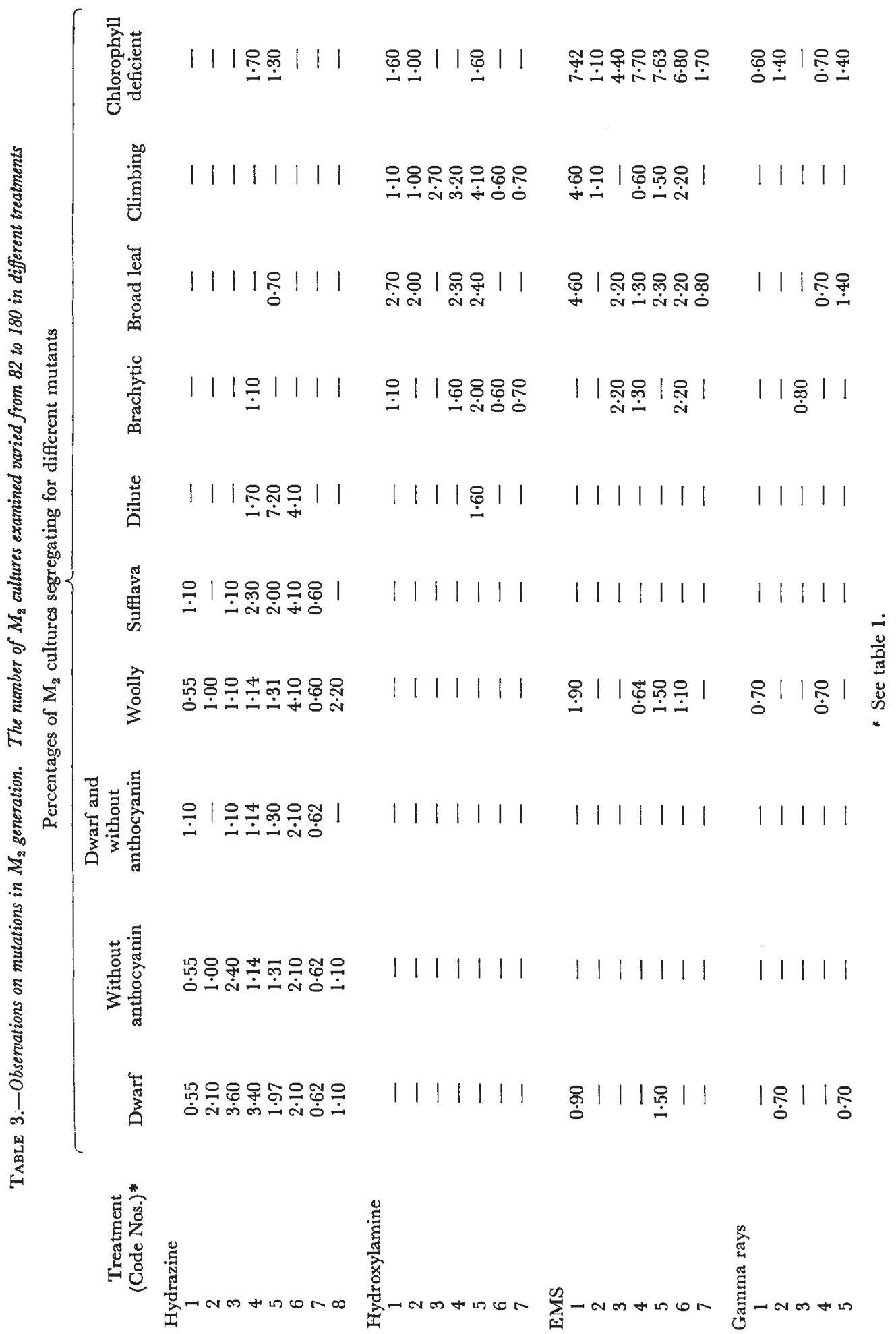


the control population (table 4). It is clear that the dwarf, dilute and climbing mutants arise through recessive gene mutations. The woolly mutant plants, on the other hand, are heterozygous for a dominant mutation.

TABLE 4

Observations on crosses between induced mutants and normal plants

\begin{tabular}{|c|c|c|c|c|c|c|c|}
\hline \multirow[t]{2}{*}{ Cross } & \multirow[t]{2}{*}{ Cross Nos. } & \multicolumn{2}{|c|}{$F_{1}$} & \multicolumn{2}{|c|}{$\mathrm{F}_{2}$} & \multirow{2}{*}{$\begin{array}{c}\chi^{2} \\
(3: 1)\end{array}$} & \multirow[t]{2}{*}{$\mathbf{P}$} \\
\hline & & & & Normal & Dwarf & & \\
\hline Dwarf $\times$ Normal & $\begin{array}{l}1 \\
2 \\
3 \\
4 \\
5\end{array}$ & \multicolumn{2}{|c|}{$\begin{array}{l}\text { Normal } \\
\text { Normal } \\
\text { Normal } \\
\text { Normal } \\
\text { Normal }\end{array}$} & $\begin{array}{r}62 \\
115 \\
104 \\
35 \\
69\end{array}$ & $\begin{array}{r}25 \\
31 \\
26 \\
9 \\
18\end{array}$ & $\begin{array}{l}0 \cdot 647 \\
1 \cdot 104 \\
1 \cdot 733 \\
0 \cdot 558 \\
0.862\end{array}$ & $\begin{array}{l}0 \cdot 50-0 \cdot 30 \\
0 \cdot 30-0 \cdot 20 \\
0 \cdot 20-0 \cdot 10 \\
0 \cdot 50-0 \cdot 30 \\
0 \cdot 50-0 \cdot 30\end{array}$ \\
\hline Total & 一 & \multicolumn{2}{|c|}{ - } & $\begin{array}{c}385 \\
\text { Normal }\end{array}$ & $\begin{array}{c}109 \\
\text { Dilute }\end{array}$ & $\begin{array}{l}2 \cdot 269 \\
(3: 1)\end{array}$ & $0 \cdot 20-0 \cdot 10$ \\
\hline Dilute $\times$ Normal & $\begin{array}{l}1 \\
2 \\
3 \\
4 \\
5\end{array}$ & \multicolumn{2}{|c|}{$\begin{array}{l}\text { Normal } \\
\text { Normal } \\
\text { Normal } \\
\text { Normal } \\
\text { Normal }\end{array}$} & $\begin{array}{r}79 \\
42 \\
120 \\
216 \\
293\end{array}$ & $\begin{array}{l}29 \\
12 \\
47 \\
63 \\
80\end{array}$ & $\begin{array}{l}0 \cdot 197 \\
0 \cdot 221 \\
0 \cdot 880 \\
0 \cdot 870 \\
2 \cdot 509\end{array}$ & $\begin{array}{l}0 \cdot 70-0 \cdot 50 \\
0 \cdot 70-0 \cdot 50 \\
0 \cdot 50-0 \cdot 30 \\
0 \cdot 50-0 \cdot 30 \\
0 \cdot 20-0 \cdot 10\end{array}$ \\
\hline Total & 一 & Normal & Woolly & 750 & 231 & $\begin{array}{l}1 \cdot 104 \\
(1: 1)\end{array}$ & $0 \cdot 30-0 \cdot 20$ \\
\hline Normal $\times$ Woolly & $\begin{array}{l}1 \\
2\end{array}$ & $\begin{array}{r}6 \\
51\end{array}$ & $\begin{array}{r}8 \\
35\end{array}$ & - & - & $\begin{array}{l}0.284 \\
2 \cdot 976\end{array}$ & $\begin{array}{l}0 \cdot 70-0 \cdot 50 \\
0 \cdot 10-0 \cdot 05\end{array}$ \\
\hline Total & - & 57 & 43 & - & - & 1.960 & $0 \cdot 20-0 \cdot 10$ \\
\hline
\end{tabular}

TABLE 5

Observations on crosses between the induced (i) and the control $(c)$ mutants

\begin{tabular}{|c|c|c|c|}
\hline \multirow[t]{2}{*}{ Cross } & \multirow[t]{2}{*}{ Cross Nos. } & \multicolumn{2}{|c|}{ Progeny } \\
\hline & & $\begin{array}{l}\text { Woolly and } \\
\text { dwarf }\end{array}$ & Dwarf \\
\hline Dwarf $(i) \times$ Woolly and dwarf $(c)$ & $\begin{array}{l}1 \\
2 \\
3\end{array}$ & $\begin{array}{l}64 \\
41 \\
33\end{array}$ & $\begin{array}{l}91 \\
63 \\
42\end{array}$ \\
\hline & & Woolly & Normal \\
\hline Dwarf and woolly $(c) \times$ Woolly $(i)$ & $\begin{array}{l}1 \\
2\end{array}$ & $\begin{array}{l}6 \\
3\end{array}$ & $\begin{array}{l}4 \\
6\end{array}$ \\
\hline & & Dilute & Normal \\
\hline Dilute $(c) \times$ Dilute $(i)$ & $\begin{array}{l}1 \\
2\end{array}$ & $\begin{array}{l}55 \\
16\end{array}$ & $\begin{array}{l}0 \\
0\end{array}$ \\
\hline
\end{tabular}

In the second series of crosses, induced mutant plants of each type were crossed with the "control " mutant plants of Butler for a test of allelism (table 5). The same locus is involved in the induced and the "control" mutants of the dwarf, woolly and dilute type, for none of the crosses gave evidence of complementation between the corresponding mutants of the two groups. 
The above analysis was limited to a few of the different types of induced mutants, and to a restricted number of plants of a particular type. It is possible that some of the other mutant plants of a particular type, say the dwarfs, may involve a different gene locus. However, the finding that all the three randomly tested dwarfs did not differ from one another suggests that most, if not all of them, arise through mutation in the same gene. In the case of the mutants not tested for allelism, the possibility that mimic gene loci (see Clayberg et al., 1966) may be involved, cannot be ruled out. However, some of the mutants like sufflava are quite characteristic, and extensive studies on induced and spontaneous mutations by several authors have failed to indicate the presence of more than one locus for independently obtained mutants of this type.

Mutants which appeared to owe their origin to a simultaneous induction of mutation at both the homologous loci, or arose from a dominant type of mutation as in the case of the woolly seedlings, could be scored in the very first generation following the treatments (table 1). Others were scored in the segregating $M_{2}$ cultures (table 3 ). Not all the $M_{1}$ plants yielded seeds; for this reason $M_{2}$ progenies were raised from a limited number of $M_{1}$ plants, which were scored as normal and showed good growth and fruit formation.

An unexpected finding (tables 1 and 3 ) is the discrepancy between the frequency of mutant seedlings such as the dwarfs in the $\mathbf{M}_{1}$ and $\mathbf{M}_{2}$ generations. On the basis that mutations at the two homologous loci are independent and have the same probability, $M_{1}$ recessive mutants of a particular type would equal $p^{2}$, and $\mathrm{M}_{2}$ cultures segregating for mutants of this type $2 p(1-p)$, where $p$ is the frequency of mutation from the dominant to the recessive condition. On this basis for small values of $p$, the number of segregating $\mathrm{M}_{2}$ cultures can be expected to be many times greater than the frequency of $M_{1}$ mutants. In contrast to this, the difference between the observed number of $M_{1}$ mutants and the $M_{2}$ cultures segregating for these mutants is not very marked (e.g. note the frequency of $M_{1}$ and $M_{2}$ dwarfs).

(ii) Second series of treatments. Attempts were made to confirm the above observations, more particularly those on the effects of hydrazine and hydroxylamine, by treatment of a larger number of seeds. Accordingly, seeds in several lots of 1000 each, were treated with comparable doses of the two chemicals. Observations recorded on the $M_{1}$ seedlings from this second series of treatments are summarised in table 6.

\section{Analysis of observations}

(i) The observations (tables 1, 3 and 6) show that hydrazine and hydroxylamine induce mutations at a number of gene loci with very different frequencies. In fact, they appear to be so selective in their action that some of the mutations were induced by only one or other of the two chemicals and not by both. This differential response of the genes is consistently observed in both series of treatments.

EMS differs from the other chemical mutagens in giving a relatively high frequency of chlorophyll-deficient seedlings of a non-specific type. In other respects, however, it corresponds closely to hydroxylamine. This is clearly seen by the similarity of the mutation spectrum associated with the two chemicals (table 3). Compared to the chemical mutagens, ionising radiation is significantly less effective in inducing mutation at most of the 
loci. To take an example, none of the radiation treatments yielded a dwarf mutant in the $\mathrm{M}_{1}$ generation, while all the different hydrazine treatments did so. It may be emphasised that the extensive study of Stubbe (1960) and others have shown that radiation treatments do induce gene mutations in tomato of the type described here. In none of these earlier studies, however, have mutants of the recessive type been observed in the $\mathbf{M}_{1}$ generation, except perhaps with relatively insignificant frequencies. Further, the radiation induced variation does not appear to be restricted to a particular group of genes.

\section{TABLE 6}

Types and frequency of $M_{1}$ mutant seedlings (second series of treatments) 1000 seeds per treatment

Code numbers and details of treatments

Hydrazine ( $p \mathrm{H} 8 \cdot 5)$

(1) $* 0 \cdot 10,28,17$

(2) $0 \cdot 10,28,17$

(3) $0 \cdot 10,28,17$

(4) $0 \cdot 15,25,28$

(5) $0 \cdot 15,25,28$

Frequency of mutant seedlings (percentage of $\mathrm{M}_{1}$ plants)

$\overbrace{\begin{array}{c}\text { Without } \\ \text { anthocyanin }\end{array}}^{\overbrace{\begin{array}{c}\text { Dwarf and } \\ \text { without } \\ \text { anthocyanin }\end{array} \text { Woolly }}}$

Hydroxylamine $(p \mathrm{H} 7 \cdot 0)$

(1) $0 \cdot 025,26,20$. (2) $0 \cdot 025,26,20$. (3) $0 \cdot 030,20,16$. (4) $0 \cdot 030,20,16$. (5) $0 \cdot 030,20,16$. No mutants observed in any of these treatments with one exception. Treatment No. 2 yielded 0.39 per cent. woolly plants.

Gamma rays (k-rads)

(1) 30 k-rads. (2) 30 k-rads. (3) 30 k-rads. (4) 40 k-rads. (5) 40 k-rads. No mutants observed in any of these treatments.

* Molar concentration, pre-soaking hours and treatment hours respectively.

(ii) Location of the affected genes. Not only does hydrazine react with genes which are little affected by the other mutagens, but a number of them are not randomly distributed in the chromosomal complement. Thus, the genes giving dwarf, woolly and dilute mutants are known to be located on chromosome 2. The genetic analysis in which the induced mutants were crossed with a control group of mutants, has confirmed that they arise from mutations of genes on chromosome 2. The mutant gene giving the sufflava condition is also known to be located on chromosome 2; however, no test of allelism has been made in this case. In contrast, none of the mutants induced by hydroxylamine with an appreciable frequency, can be traced to any of the known loci on chromosome 2.

It should be emphasised that scoring of variation on the present basis was favoured for those genes which give mutants of a characteristic type. Both hydrazine and hydroxylamine are expected to have induced other mutations also. But these apparently escaped detection. It is clear, however, that for the limited number of mutants which could be readily scored, the two chemicals show a widely different effect. 


\section{Discussion}

Chemical mutagens like hydrazine and hydroxylamine, whose action can be interpreted in terms of molecular mechanisms, induce mutation in both micro (Freese, 1963; Benzer, 1961) and higher organisms, if the condition of treatment can be sufficiently controlled. In the case of seed treatment, it does not appear to be too difficult to maintain these conditions. The finding indicates that notwithstanding the difference in the organisation of genetic material in the micro- and macro-organism, the mutation process in the two may be basically alike. Alternatively the difference in organisation may not be of a very basic nature.

(i) Mutation rates. It has been widely believed that chemical mutagens like EMS can be far more effective than ionising radiations in inducing mutations (Ehrenberg et al., 1961; Fahmy and Fahmy, 1956). Few studies of this nature, however, have been based on the specific locus method. The most common practice in the case of plants is to score seedlings showing various types of chlorophyll deficiencies, without attempting to trace the different variegated or albino conditions to any of the discrete loci in the chromosomes. The marked sensitivity of a number of genes to the action of chemical mutagens is clearly shown by the present analysis. That a number of genes in tomato are particularly sensitive to hydrazine, compared to other mutagens, can be seen from the following observations. Following treatment with this chemical, several types of mutant seedlings could be observed in the very first generation $\left(\mathbf{M}_{\mathbf{1}}\right)$ of treatment (tables 1 and 6 ). The genetic analysis with a number of these mutants, particularly the dwarfs, has shown that a recessive gene mutation is involved (tables 4 and 5). The lack of complementation, observed in crosses with the control mutant stocks, has helped to determine the locus involved. The $M_{1}$ mutant seedlings arise from simultaneous mutation of the locus concerned in both the homologus chromosomes. This indicates a very high degree of effectiveness of the mutagen. In the several control series, mutants for these genes were hardly found at all. The different radiation treatments were relatively much less effective in inducing mutations of these genes. Thus, all the 13 lots of seeds treated with hydrazine consistently showed mutation at the $d$ locus, and as explained earlier, some of the mutant seedlings were recovered in the $M_{1}$ generation. In contrast, the radiation treatment in most cases failed to induce mutation of this and other genes affected by hydrazine. It is true that mutations of some of these genes, following various radiation treatments, have been reported by earlier authors (e.g. Stubbe, 1957, 1960; Yu and Yeager, 1960). However, the mutation frequency observed in these studies was insignificant compared to the rates obtained in the course of the present analysis.

(ii) Differential response of the genes. Auerbach (1965) has said that mutagen specificity offers possibilities for analysis that so far have been almost neglected. It has been found in the present study that some genes are particularly sensitive to hydrazine. The relative resistance of these genes to hydroxylamine is also quite clear. The different hydroxylamine treatments, involving 12 separate lots of seeds, failed mostly to induce mutations at these loci, although they did affect some other genes quite consistently. Thus the broad-leaved, brachytic and climbing type of mutants were commonly obtained in the $\mathrm{M}_{2}$ cultures with this chemical. Further, EMS corresponds more closely to hydroxylamine than to hydrazine in its mutation spectrum. 
Both the differential response of the affected genes to the different chemical mutagens, and the extreme sensitivity of some of them, point to the conclusion that the mutation process with a chemical like hydrazine is very different from that with ionising radiations on the one hand, and other chemical mutagens on the other. It seems likely that the difference is primarily a function of the known reactivity of this chemical with a particular base of the DNA molecule. However, Auerbach (1965) has pointed out that the response of particular genes to base specific mutagens cannot always be attributed to the reaction between mutagen and DNA. She has considered several other possible explanations, including one based on the protection of DNA by accessory substances such as the repressor material.

Several of the genes which are sensitive to hydrazine are located on chromosome 2 which has received considerable attention because it accounts for nearly 16 per cent. of the mapped genes in tomato (Clayberg et al., 1966). It has been generally concluded that factors of a karyomorphological nature can not account for this asymmetry (Rick, 1959). The most probable explanation seems to be that genes on chromosome 2 show greater spontaneous mutability and are more readily detected for this reason. Perhaps the factors which contribute to the sensitivity of some of these genes to hydrazine are also the ones responsible for their higher spontaneous mutation rate.

The $\mathrm{M}_{1}$ plants, used for raising the small number of $\mathrm{M}_{2}$ progenies, did not constitute a random sample of the total population, and included a greater proportion of those which were least affected by the mutagenic treatments. It would appear, however, that the discrepancy between the observed frequency of recessive mutants, such as the dwarfs, in the $M_{1}$ and $M_{2}$ generations is not entirely a function of the smaller size of the $M_{2}$ material. The deviation from the expected values is too large to be fully explained in this way. The unexpectedly large number of mutants observed in the $M_{1}$ generation seems to suggest that with a mutagen like hydrazine, the probability of both the homologous loci responding simultaneously is greater than that expected on the basis of independent mutational events.

In tomato seeds, the primordia for the first several nodes and their subtending leaves already exist in the embryo. This means that mutants like the dwarfs are not expected to appear in the $\mathbf{M}_{1}$ seedlings. They are also not expected to occur in a non-chimeric condition at the adult stage in the $\mathrm{M}_{1}$ generation, unless all cells of the meristem mutate in the same way. This requires a very high rate of directed mutation. The production of true breeding homozygous $M_{1}$ mutants like the dwarfs, as a result of hydrazine treatment, is thus of considerable interest. No explanation other than one based on the extreme mutagenic reactivity of this chemical appears likely. It seems clear, as concluded above, that some of the base specific chemicals may differ greatly from other mutagens in specificity as well as effectiveness.

Finally, one of the mutants induced by hydrazine was dwarf and lacked anthocyanin. At first sight it appears that this may be a double mutant, involving two separate loci (e.g. aw and $d$ ). However, a close comparison with known double mutants of this type shows that this may not be so. It appears more likely that a single gene mutation is involved, and that this mutant has not been known earlier. 


\section{Summary}

1. Hydrazine, hydroxylamine and ethyl methane sulfonate have been tested for their mutagenic effects on the tomato plant.

2. A number of genes are particularly sensitive to hydrazine. Homozygous mutants for a number of these genes were consistently obtained in the $M_{1}$ generation following treatment of seeds with this chemical.

3. These genes were little affected by other chemical mutagens, which did, however, induce mutation at some other loci.

4. Several of the hydrazine-sensitive genes, like 16 per cent. of the 150 genes mapped in tomato, are in chromosome 2.

\section{RefERENCES}

Auerbach, c. 1965. Past achievements and future tasks of research in chemical mutagenesis. In Genetics Today, Vol. 2, pp. 275-284, ed. Geerts, S. J. Pergamon Press, Oxford.

Benzer, s. 1961. On the topography of the genetic fine structure. Proc. Nat. Acad. Sci., U.S., 47, 403-426.

BRown, D. M., AND SCHELl, P. 1961. The reaction of hydroxylamine with cytosine and related compounds. J. Mol. Biol., 3, 709-710.

GLAYBERG, C. D., BUTLER, L., RICK, C. M., AND YOUNG, P. A. 1960. Second list of known genes in the tomato. $\mathcal{F}$. Hered., $51,167-174$.

GLAYBERG, C. D., BUTLER, L., KERR, E. A., RICK, C. M., AND ROBINSON, R. w. 1966. Third list of known genes in the tomato. F. Hered., 57, 189-196.

EHRENBERG, L., GUSTAFSSON, A., AND LUNDQUIST, U. 1961. Viable mutations induced in barley by ionizing radiations and chemical mutagens. Hereditas, 47, 243-283.

FAHMY, O. G., AND FAHMY, M. J. 1956. Differential genetic response to the alkylating mutagens and X-radiation. 7. Genet., 54, 146-164.

FREESE, E. 1963. Molecular mechanism of mutations. In Molecular Genetics, Part I, pp. 207-269, ed. Taylor, J. H. Academic Press, New York.

FREESE, E., FREESE, E. B., AND BAUTZ, E. 1961a. Hydroxylamine as a mutagenic and inactivating agent. F. Mol. Biol., 3, 133-134.

FREESE, E., BAUTZ, E., AND FREESE, E. B. 1961 b. The chemical and mutagenic specificity of hydroxylamine. Proc. Nat. Acad. Sci., U.S., 47, 845-855.

KRIEG, D. R. 1963. Ethyl methane sulfonate induced reversion of bacteriophage $\mathrm{T}_{4} \mathrm{rII}$ mutants. Genetics, 48, 561-580.

Malling, H. V. 1966. Hydroxylamine as a mutagenic agent for Neurospora crassa. Mutation Res., 3, 470-476.

RICK, G. M. 1959. Non-random gene distribution among tomato chromosome. Proc. Nat. Acad.Sci., U.S., 45, 1515-1519.

RiCK, G. M., AND BUTLER, L. 1956. Cytogenetics of the tomato. Adv. Genetics, 8, 267-382.

SALGANIK, R. I. 1963. Application of radiation denaturation of DNA in combination with chemical mutagens to affect the mutational process. In Genetics Today, Vol. I, p. 55, ed. Geerts, S. J. Pergamon Press, Oxford.

StuBbe, H. 1957. Mutanten der Kulturtomate L. esculentum I. Kulturpfl., 5, 190-220.

StUBbe, H. 1960. Mutanten der Wild tomate L. pimpinellifolium I. Kulturpfl., 8, 110-137.

YU, s., AND YEAGER, A. F. 1960. Ten heritable mutations found in the tomato following irradiation with X-rays and thermal neutrons. Proc. Amer. Soc. Hort. Sci., 76, 538-542. 